\title{
Diversity-oriented synthesis derived indole based spiro and fused small molecules kills artemisinin-resistant Plasmodium falciparum
}

\author{
Akshaykumar Nayak ${ }^{1 \dagger}$, Himani Saxena ${ }^{1 \dagger}$, Chandramohan Bathula $^{2}$, Tarkeshwar Kumar $^{3}$, Souvik Bhattacharjee $^{3}$,
} Subhabrata Sen ${ }^{2^{*}}$ and Ashish Gupta ${ }^{1 *}$ (i)

\begin{abstract}
Background: Despite numerous efforts to eradicate the disease, malaria continues to remain one of the most dangerous infectious diseases plaguing the world. In the absence of any effective vaccines and with emerging drug resistance in the parasite against the majority of anti-malarial drugs, the search for new drugs is urgently needed for effective malaria treatment.
\end{abstract}

Methods: The goal of the present study was to examine the compound library, based on indoles generated through diversity-oriented synthesis belonging to four different architecture, i.e., 1-aryltetrahydro/dihydro- $\beta$-carbolines and piperidine/pyrrolidine-fused indole derivatives, for their in vitro anti-plasmodial activity. Trifluoroacetic acid catalyzed transformation involving tryptamine and various aldehydes/ketones provided the library.

Results: Among all the compounds screened, 1 -aryltetrahydro- $\beta$-carbolines 2 and 3 displayed significant anti-plasmodial activity against both the artemisinin-sensitive and artemisinin-resistant strain of Plasmodium falciparum. It was observed that these compounds inhibited the overall parasite growth in intra-erythrocytic developmental cycle (IDC) via reactive oxygen species-mediated parasitic death and thus could be potential anti-malarial compounds.

Conclusion: Overall the compounds 2 and 3 identified in this study shows promising anti-plasmodial activity that can kill both artemisinin-sensitive and artemisinin-resistant strains of P. falciparum.

Keywords: Plasmodium, Artemisinin, Artemisinin-resistance, DOS, Indole

\section{Background}

Since primitive times, malaria, a mosquito-borne infectious disease, has remained the leading cause of mortality from any parasitic disease around the world. It has been estimated that Plasmodium spp., the causative agent of malaria, infected 228 million people, accounting for

\footnotetext{
*Correspondence: subhabrata.sen@snu.edu.in; ag315@snu.edu.in

${ }^{\dagger}$ Akshaykumar Nayak and Himani Saxena contributed equally to this work ${ }^{1}$ Epigenetics \& Human Disease Laboratory, Department of Life Sciences, Shiv Nadar University, Uttar Pradesh, NH-91, Tehsil-Dadri, Greater Noida 201314, India

2 Department of Chemistry, Shiv Nadar University, Uttar Pradesh, Tehsil-Dadri, Greater Noida 201314, India

Full list of author information is available at the end of the article
}

about half a million deaths in 2019 , mostly affecting poor people living in tropical and sub-tropical regions of the world [1]. Unlike other Plasmodium species, Plasmodium falciparum causes the severe form of malaria and poses higher risk of death due to associated neurological, renal or cardiological complications [2]. To reduce the number of malaria-related cases and mortality, most of the malaria control programmes besides using other control measures, rely heavily on killing the malarial parasite by anti-malarial chemotherapy [3]. Quinine, a plant derived chemical extracted from the bark of the Cinchona tree, was used to treat malaria from as early as the $1600 \mathrm{~s}$ and is still used as second-line therapy for the management 
of uncomplicated malaria in Africa when the first-line drug either fails or is not available [4-7]. With the range of adverse side effects experienced by the use of quinine, the search for a safe and most effective anti-malarial medicine led to the discovery of chloroquine, followed by many synthetic anti-malarials, e.g., sulfadoxinepyrimethamine, amodiaquine and mefloquine $[5,6,8,9]$. Despite their early success in therapeutic management of malaria, their overuse contributed to the development and spread of resistance against these drugs by the malarial parasite. Undoubtedly, the unregulated use of these drugs as monotherapy further accelerated their failing therapeutic efficacy [6, 9-11].

At present, the most potent and successful drug available for the treatment of both severe and uncomplicated malaria is artemisinin, which was derived from the Qinghao plant (Artemisia annua) in the 1970s [5]. Artemisinin is frequently used in combination with a partner anti-malarial drug to overcome its pharmacokinetic limitations (such as poor bioavailability, low solubility in water and a relatively shorter half-life in vivo $(\sim 2.5 \mathrm{~h})$ ) and to protect its efficacy against parasite resistance for a longer period of time [5]. Presently, five recommended artemisinin-based combinations include combinations of artemisinin derivates, such as artemisinin, dihydroartemisinin, artemether, artesunate, with lumefantrine, mefloquine, amodiaquine, sulfadoxine/pyrimethamine, piperaquine, and chlorproguanil/dapsone [5]. Artemisinins are particularly active against the ring and mature trophozoite form of asexual life-cycle stage of parasites persisting within infected red blood cells. However, a sub-population of ring form of the parasite may tolerate artemisinin by becoming temporarily dormant or sequestered to return after a few days or weeks, eventually causing the failure of treatment $[6,12]$. It is for this reason that artemisinin monotherapy is not preferred and is recommended to be used only with longer-acting partner anti-malarial drug that would kill the surviving dormant form of the parasite [11, 13]. Although artemisinin-based combination therapy (ACT) had a marked effect on malaria cases globally, the appearance of artemisinin-resistant cases in Southeast Asia, especially in the eastern Greater Mekong Sub-region, is cause for concern [14-17]. By relying so heavily upon the use of ACT, eventually this valuable anti-malarial drug will become ineffective, given the history of resistance development in the parasite to most anti-malarials. Bringing safe and new anti-malarial drug candidates with diverse chemical structures and mechanism of action into clinical trials is critical to combat emerging anti-malarial drug resistance in the parasite.

Over time, new concepts in organic synthesis and molecular design, such as fragment-based drug discovery
(FBDD), ligand-based drug discovery (LBDD), biologyoriented synthesis (BIOS), and diversity-oriented synthesis (DOS) began to evolve. Compared to traditional drug discovery platforms, these methods have not only expedited the process of bringing new drugs onto the market but also have helped in providing drugs with better specificity towards the target and lesser toxicity. DOS has particularly emerged as a synthetic approach that is used for the design and construction of novel, small molecule libraries containing a high degree of structural and stereo-chemical diversity [18, 19]. Screening of DOSderived compound libraries has led to identification of many novel and biologically useful small molecules known for their antibacterial, antifungal, antiparasitic, and anticancer properties [20-25]. Accordingly, the present work aimed to screen and evaluate compounds of DOS library (comprised of 11 indole-based heterocycles which are connected to piperidine or pyrrolidine molecules either through bond fusion or via spiro linkage) for their efficacy in killing both wild-type and artemisininresistant strains of $P$. falciparum in vitro. These compounds can be segregated into 4 different structures. The initial reaction involved trifluoroacetic acid (TFA) catalyzed condensation reactions of tryptamines with various aldehydes/ ketones to afford various library molecules (Experimental procedure section, Additional file 1). Few of them were further transformed to newer compounds by $\mathrm{N}$-bromosuccinimide (NBS)-mediated oxidation or ring contraction (Experimental procedure section, Additional file 1).

The study's screening assay identified that 1 -aryltetrahyro- $\beta$-carboline class of compounds possess significant anti-plasmodial activity. Further screening of two best compounds, i.e., 2 and 3, showed their potential to kill both wild-type and artemisinin-resistant strains. Also shown was that compound 3 can induce significant reactive oxygen species (ROS) generation in malaria parasites, providing insight into the mechanism of compound 3-induced parasite death.

\section{Methods}

\section{Compound designs and synthesis}

The DOS library screened here is comprised of 11 compounds belonging to four different structural classes of compounds, as described in Additional file 1 and previously published work [26, 27]. They are dihydro and tetrahydro- $\beta$-carbolines, piperidine and pyrrolidinefused tetrahyro- $\beta$-carbolines and spiropyrrolooxoindoles (Additional file 1: Figure S1A). Tryptamine is the appropriate substrate which when reacted with aldehydes/ ketones in presence of catalytic TFA, undergoes condensation to provide a preliminary set of scaffolds $1 \rightarrow 3,9$ and 11 (Additional file 1: Figure S1B). Compound 2 and a 
few more tetrahydro- $\beta$-carbolines $5 \mathrm{a}-8 \mathrm{a}$ were oxidized to dihydro- $\beta$-carbolines $4-8$ in presence of NBS $(N$-Bromosuccinimide) and compound 9 underwent NBS-mediated ring contraction to afford a diastereomeric mixtures of 10a/b (Additional file 1: Figure S1B). Detailed synthesis and characterization of compounds is provided in Additional file 1.

\section{Parasite culture}

Plasmodium falciparum artemisinin-sensitive parental 3D7 strain and artemisinin-resistant R539T strain (expressing PfKelch13/PF3D7_1343700 with R539T mutation) were cultured in $\mathrm{O}+$ ve erythrocytes at $37^{\circ} \mathrm{C}$. The generation and characterization of artemisininresistant parasites were reported earlier [28, 29]. RPMI1640 media (supplemented with $0.5 \%$ albumax, $0.2 \%$ sodium bicarbonate, $50 \mu \mathrm{g} / \mathrm{ml}$ of hypoxanthine, and $10 \mu \mathrm{g} / \mathrm{ml}$ of gentamicin) and mixture gas environment (90\% nitrogen, $5 \%$ oxygen and $5 \%$ carbon dioxide) was used for culture. For routine culture, haematocrit was maintained at 5\% and the stages and growth of parasite was routinely monitored by microscopic examination of Giemsa-stained blood smears. Synchronization of parasite culture was done using $5 \%$ sorbitol method as discussed elsewhere [30].

\section{Parasite growth inhibition assay}

To investigate the inhibitory potential of compounds, parasite growth inhibition assay was performed with parasite culture synchronized in ring stage and seeded in 12-well plates at $\sim 1 \%$ parasitaemia. These parasites were treated with compounds at various concentrations for $48 \mathrm{~h}$. Microscopy-based examination of the Giemsastained blood smears of parasite culture treated either with compounds or DMSO (control) were performed at 0 and $48 \mathrm{~h}$ and parasites in different stages of intra-erythrocytic developmental cycle (IDC) were counted. For the calculation of $\mathrm{IC}_{50}$ values, GraphPad Prism 5.0 software was used.

\section{Measurement of ROS levels}

The detection of ROS level in parasitized-erythrocyte was performed using $\mathrm{H}_{2}$ DCFDA dye. For this, parasite culture was treated with compounds for $48 \mathrm{~h}$ and then washed with $1 \mathrm{X}$ PBS. Treated parasites were incubated with $\mathrm{H}_{2}$ DCFDA dye $(5 \mu \mathrm{M})$ and incubated for $20 \mathrm{~min}$ in dark and subsequently washed using $1 \mathrm{X}$ PBS. Thin blood smears were prepared on glass slides and mounted using anti-fade DAPI. ROS generation was detected under confocal microscope (Nikon Eclipse Ti2-E) using 100× magnification. Intensity of generated signal was calculated using NIS-Elements AR analysis 5.20.02 software.

\section{Results}

Evaluation of DOS-derived compounds for their anti-plasmodial activity

The DOS-derived compound library (Additional file 1: Figure S1) was screened for anti-plasmodial activity using parasite growth inhibition assay. For this, synchronized ring-stage parasite culture of 3D7 strain was treated with the compounds at $5 \mu \mathrm{M}$ concentration for $48 \mathrm{~h}$. Parasites treated with DMSO were used as control. Parasitaemia was measured at 0 and $48 \mathrm{~h}$ post-treatment and graph was plotted for the average value of three independent sets of experiments (Fig. 1a). Fifty percent parasite growth inhibition was reserved as cut-off value for selection of compounds to have anti-plasmodial activity. Results showed that 1 -aryltetrahydro- $\beta$-carbolines $1-3$ and 1-aryldihydro- $\beta$-carbolines $4-8$ were most efficacious, demonstrating more than $50 \%$ inhibition of Plasmodium growth (Fig. 1a).

Intra-erythrocytic developmental cycle (IDC) is an asexual replicative phase characterized by the parasite progression through three successive morphological stages as ring, trophozoite and schizont. Next, the effect of 1-aryl-dihydro/tetrahydro- $\beta$-carbolines $1-8$ on growth progression of Plasmodium during the IDC in presence of these compounds was evaluated. Results showed that compounds 1-8 killed all the IDC stages of the parasite as no stage-specific growth inhibition was observed (Fig. 1b). Figure 1b shows the percentage of parasite population in different stages of IDC in control and treated samples at 0 and $48 \mathrm{~h}$ post-treatment. Together the phenotypic screening identified 8 compounds effective in killing $P$. falciparum parasites with their toxicity independent of the parasite stages.

\section{Compounds 2 and 3 inhibit artemisinin-resistant parasite growth}

After observing significant inhibitory effect of $\beta$-carboline derivatives on wild-type 3D7 strain growth and survival, the interest was to determine the inhibitory effect of the most potent $\beta$-carboline derivatives 2 and 3 on artemisinin-resistant P. falciparum (R539T) strain. Primarily to determine the artemisinin-resistance of R539T strain, synchronized ring-stage parasites of 3D7 and R539T parasite strains were treated with different concentrations of artemisinin (1 nM, $10 \mathrm{nM}$, $100 \mathrm{nM}, 1 \mu \mathrm{M}, 10 \mu \mathrm{M}, 100 \mu \mathrm{M}$ ) or DMSO (control) for $48 \mathrm{~h}$. Results showed significant resistance to artemisinin in $\mathrm{R} 539 \mathrm{~T}$ parasite (Fig. 2a). $\mathrm{IC}_{50}$ value of artemisinin was calculated to be $3.86 \mathrm{nM}$ and $40.3 \mathrm{nM}$ for artemisinin-sensitive 3D7 and artemisinin-resistant R539T parasites, respectively. Next, to determine the effect of selected compounds ( $\beta$-carboline derivatives 2 and 3 ) on artemisinin-resistant parasite, synchronized ring-stage 
a

b

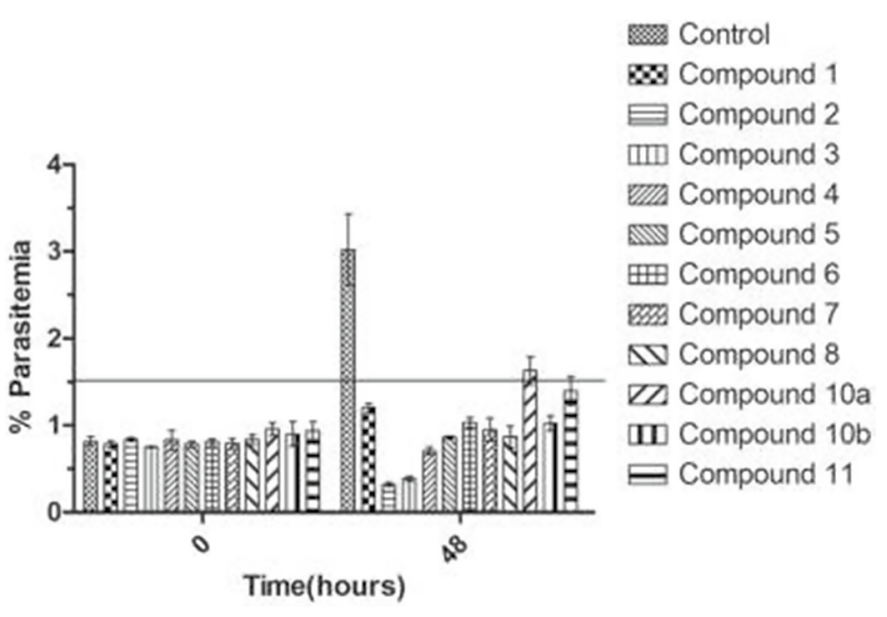

\begin{tabular}{|c|c|c|c|c|c|c|}
\hline $\begin{array}{c}\text { Time } \\
\text { (post- }\end{array}$ & & 0 hour & & & 48 hour & \\
\hline Compound & Ring & Trophozoite & Schizont & Ring & Trophozoite & Schizont \\
\hline $\begin{array}{l}\text { Control } \\
\text { (DMSO) }\end{array}$ & $\begin{array}{c}96.66 \\
( \pm 5.77)\end{array}$ & $\begin{array}{c}3.33 \\
( \pm 5.77)\end{array}$ & 0 & $\begin{array}{c}78.33 \\
( \pm 2.88)\end{array}$ & $\begin{array}{c}21.66 \\
( \pm 2.88)\end{array}$ & 0 \\
\hline $\begin{array}{c}\text { Compound } \\
1\end{array}$ & $\begin{array}{c}98.33 \\
( \pm 2.88)\end{array}$ & $\begin{array}{c}1.66 \\
( \pm 2.88)\end{array}$ & 0 & $\begin{array}{c}56.66 \\
( \pm 2.88)\end{array}$ & $\begin{array}{c}26.66 \\
( \pm 2.88)\end{array}$ & $\begin{array}{c}16.66 \\
( \pm 5.77)\end{array}$ \\
\hline $\begin{array}{c}\text { Compound } \\
2\end{array}$ & $\begin{array}{l}100 \\
( \pm 0)\end{array}$ & 0 & 0 & $\begin{array}{c}53.33 \\
( \pm 2.88)\end{array}$ & $\begin{array}{c}21.66 \\
( \pm 2.88)\end{array}$ & $\begin{array}{c}25 \\
( \pm 5)\end{array}$ \\
\hline $\begin{array}{c}\text { Compound } \\
3\end{array}$ & $\begin{array}{l}100 \\
( \pm 0)\end{array}$ & 0 & 0 & $\begin{array}{c}53.33 \\
( \pm 5.77)\end{array}$ & $\begin{array}{c}23.33 \\
( \pm 5.77)\end{array}$ & $\begin{array}{c}23.33 \\
( \pm 5.77)\end{array}$ \\
\hline $\begin{array}{c}\text { Compound } \\
4\end{array}$ & $\begin{array}{c}98.33 \\
( \pm 2.88)\end{array}$ & $\begin{array}{c}1.66 \\
( \pm 2.88)\end{array}$ & 0 & $\begin{array}{c}53.33 \\
( \pm 5.77)\end{array}$ & $\begin{array}{c}23.33 \\
( \pm 2.88)\end{array}$ & $\begin{array}{c}23.33 \\
( \pm 2.88)\end{array}$ \\
\hline $\begin{array}{c}\text { Compound } \\
5\end{array}$ & $\begin{array}{l}100 \\
( \pm 0)\end{array}$ & 0 & 0 & $\begin{array}{c}51.66 \\
( \pm 2.88)\end{array}$ & $\begin{array}{c}26.66 \\
( \pm 2.88)\end{array}$ & $\begin{array}{c}26.66 \\
( \pm 2.88)\end{array}$ \\
\hline $\begin{array}{c}\text { Compound } \\
6\end{array}$ & $\begin{array}{l}100 \\
( \pm 0)\end{array}$ & 0 & 0 & $\begin{array}{c}61.66 \\
( \pm 7.63)\end{array}$ & $\begin{array}{c}25 \\
( \pm 5)\end{array}$ & $\begin{array}{c}13.33 \\
( \pm 5.77)\end{array}$ \\
\hline $\begin{array}{c}\text { Compound } \\
7\end{array}$ & $\begin{array}{c}96.66 \\
( \pm 5.77)\end{array}$ & $\begin{array}{c}3.33 \\
( \pm 5.77)\end{array}$ & 0 & $\begin{array}{c}53.33 \\
( \pm 2.88)\end{array}$ & $\begin{array}{c}26.66 \\
( \pm 2.88)\end{array}$ & $\begin{array}{c}20 \\
( \pm 5)\end{array}$ \\
\hline $\begin{array}{c}\text { Compound } \\
8\end{array}$ & $\begin{array}{l}100 \\
( \pm 0)\end{array}$ & 0 & 0 & $\begin{array}{c}55 \\
( \pm 5) \\
\end{array}$ & $\begin{array}{c}21.66 \\
( \pm 2.88)\end{array}$ & $\begin{array}{c}18.33 \\
( \pm 7.63)\end{array}$ \\
\hline $\begin{array}{c}\text { Compound } \\
10 \mathrm{a}\end{array}$ & $\begin{array}{c}98.33 \\
( \pm 2.88)\end{array}$ & $\begin{array}{c}1.66 \\
( \pm 2.88)\end{array}$ & 0 & $\begin{array}{c}68.33 \\
( \pm 7.63)\end{array}$ & $\begin{array}{c}11.66 \\
( \pm 2.88)\end{array}$ & $\begin{array}{c}20 \\
( \pm 8.66)\end{array}$ \\
\hline $\begin{array}{c}\text { Compound } \\
10 \mathrm{~b}\end{array}$ & $\begin{array}{c}96.66 \\
( \pm 5.77)\end{array}$ & $\begin{array}{c}3.33 \\
( \pm 5.77)\end{array}$ & 0 & $\begin{array}{c}93.33 \\
( \pm 5.77)\end{array}$ & $\begin{array}{c}3.33 \\
( \pm 5.77)\end{array}$ & $\begin{array}{c}3.33 \\
( \pm 5.77)\end{array}$ \\
\hline $\begin{array}{c}\text { Compound } \\
11\end{array}$ & $\begin{array}{c}96.66 \\
( \pm 5.77)\end{array}$ & $\begin{array}{c}3.33 \\
( \pm 5.77)\end{array}$ & 0 & $\begin{array}{c}65 \\
( \pm 10)\end{array}$ & $\begin{array}{c}13.33 \\
( \pm 2.88)\end{array}$ & $\begin{array}{c}21.66 \\
( \pm 10.40)\end{array}$ \\
\hline
\end{tabular}

Fig. 1 Screening of DOS-synthesised compounds for anti-plasmodial activity. a Synchronized parasite culture in ring stage were seeded to adjust parasitaemia to $1 \%$. This synchronized culture was then treated either with DMSO or compounds $(5 \mu \mathrm{M})$ for $48 \mathrm{~h}$. Giemsa-stained slides were prepared at 0 and $48 \mathrm{~h}$ post-treatment to monitor the parasitaemia. Graphs were prepared for the average value of three independent experiments performed in duplicate with \pm SD. $\mathbf{b}$ Parasites at different stages of the IDC at 0 and $48 \mathrm{~h}$ post-treatment were calculated. Table shows the percentage of remaining parasites in different stages of IDC from three independent experiments with $\pm S D$ 


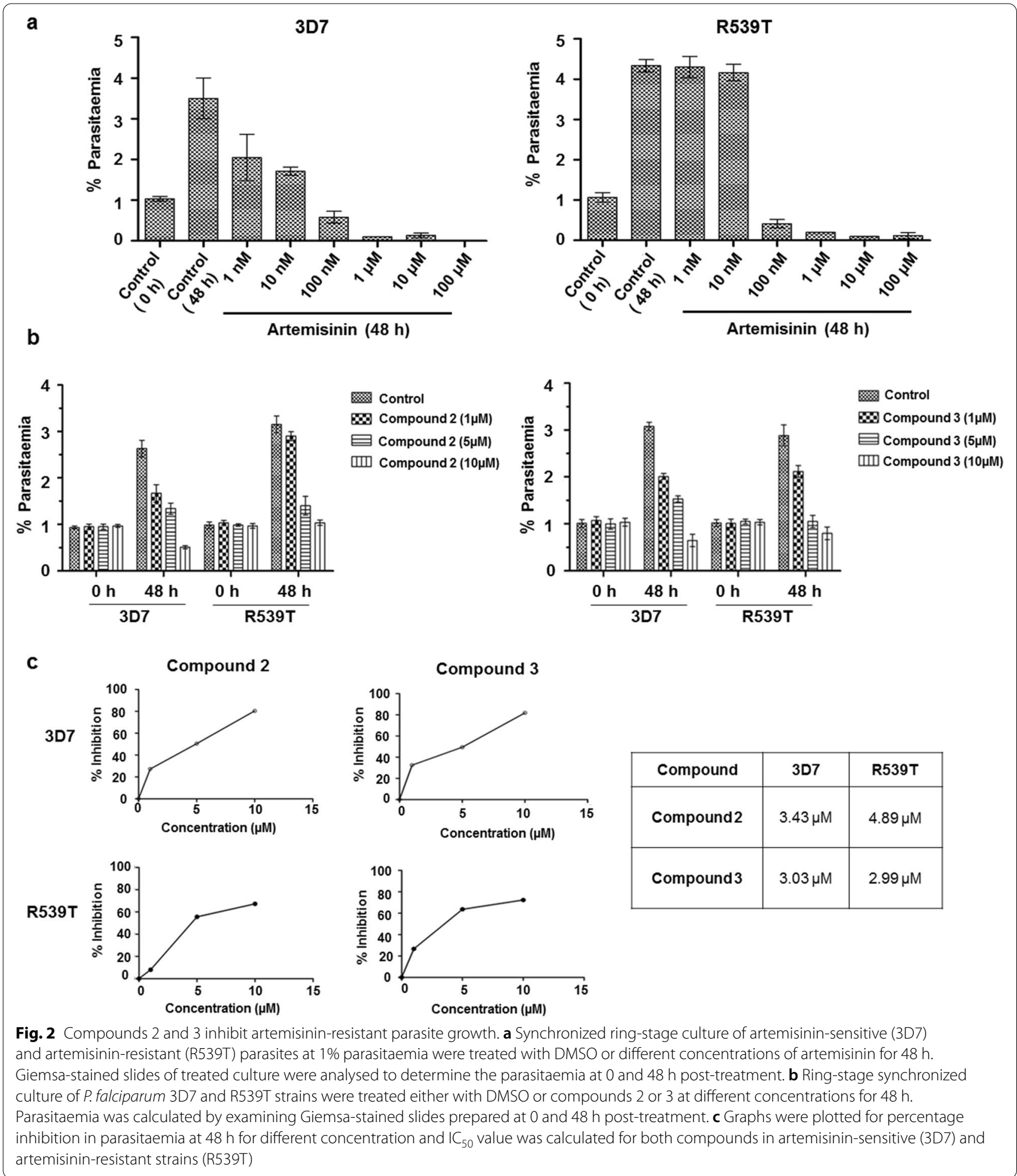

parasites of R539T strain were incubated with different concentrations $(1 \mu \mathrm{M}, 5 \mu \mathrm{M}, 10 \mu \mathrm{M})$ of these two compounds or DMSO (control) for $48 \mathrm{~h}$. The parental 3D7 parasites were also treated simultaneously in similar manner for comparative analysis. Results showed corresponding reduction in parasitaemia with increasing concentration of these compounds in both artemisininsensitive (3D7) and artemisinin-resistant (R539T) strains 
(Fig. 2b). The $\mathrm{IC}_{50}$ value of compound 2 was calculated to be $3.43 \pm 0.77 \mu \mathrm{M}$ and $4.89 \pm 0.91 \mu \mathrm{M}$ for $3 \mathrm{D} 7$ and R539T strains, respectively, while for compound 3 it was $3.03 \pm 0.24 \mu \mathrm{M}$ and $2.99 \pm 0.48 \mu \mathrm{M}$ for $3 \mathrm{D} 7$ and $\mathrm{R} 539 \mathrm{~T}$ strains, respectively (Fig. 2c). Together these findings showed that compounds 2 and 3 can potently inhibit the growth and survival of both wild-type and artemisininresistant parasites.

Since compounds 2 and 3 showed promising anti-plasmodial activity, the SwissADME web tool [31] was used to determine their suitability as potential drug candidates through analysing some of the key ADME parameters, such as solubility and lipophilicity. The aqueous solubility (Log S[ESOL]) for compounds 2 and 3 was calculated to be -5.65 and -4.01 , respectively, and show that these compounds are fairly soluble in water. Similarly, lipophilicity $\left(\log \mathrm{P}_{\mathrm{o} / \mathrm{w}}\right)$ for compounds 2 and 3 was calculated to be 3.09 and 3, respectively, which are within the acceptable ADME parameters.

\section{Compounds 2 and 3 enhance ROS generation in Plasmodium falciparum}

To determine whether the growth inhibitory effect of $\beta$-carbolines compounds 2 and 3 was associated with generation of oxidative stress, the level of ROS in the presence of these compounds was examined by the $\mathrm{H}_{2}$ DCFDA dye staining method. For this, Plasmodium infected red blood cells (RBCs) were treated with compounds 2 and 3 for $48 \mathrm{~h}$ followed by staining with $\mathrm{H}_{2}$ DCFDA dye. ROS generation was detected using fluorescence microscopy and the result showed significant enhancement in the level of ROS generation with compound 3 compared to control (Fig. 3). Compound 2 -treated parasites also showed ROS generation, however at lower levels compared to compound 3.

\section{Discussion}

Despite availability of a wide variety of anti-malarial drugs, including quinine, chloroquine, sulfadoxine, atovaquone, primaquine, artemisinin, and their derivatives, increasing cases of drug resistance in malaria parasites and transmission of resistant parasites in new areas is throwing a challenge for worldwide efforts to eradicate malaria [32, 33]. There is a need to come up with new anti-malarials with different mechanisms of action. DOS method has led to generation of libraries of small molecules based on complex structure scaffolds and has successfully played a role in the discovery of several bioactive compounds that have either emerged as drug leads or have helped enhance the knowledge of complex biological processes [34-36].

The presence of indole-based heterocycles in many bioactive natural products has prompted scientists to use indole scaffold for developing libraries of a diverse range of compounds that are known to show promising activity against many human diseases, including cancer, microbial infection and parasitic diseases [37, 38]. This has encouraged synthesis of libraries comprising of molecules inspired from various indole heterocycles and natural products as potential lead candidates against malaria parasites [39-42]. In this study, a library of indole- based spiro and fused small molecules were screened and among all the compounds tested, compounds 2 and 3 exhibited toxicity against all the parasitic stages of IDC with similar levels of lethality for artemisinin-sensitive and artemisinin-resistant strains of $P$. falciparum. This suggest that these compounds might have a dissimilar mode of action compared to artemisinin for killing malaria parasite. The compounds showed strong antiplasmodial activity at a concentration range of 3-5 $\mu \mathrm{M}$ which is in comparable range to other indole-based antiplasmodial compounds shown in previous studies [40, 41].

Compound 3 induced oxidative stress by enhancing production of ROS, which could be a possible mechanism of action of this compound in killing malaria parasites. ROS are known to damage DNA, RNA and can oxidize proteins and lipids, leading to death of a cell. Bioactive indole compounds are shown to bind with multiple receptors, and thus can act by multiple mechanisms making them attractive chemical molecules for developing novel therapeutic compounds [38]. Hit compounds identified in this study can be further refined and developed for use as anti-malarial compounds or can be used as a scaffold to develop artemisinin-based hybrid molecules [43].

\section{Conclusions}

Overall, this study displays the potential of 1 -aryltetrahydro- $\beta$-carbolines compounds as anti-malarials that can kill artemisinin-resistant parasites. This opens the possibility to develop them or their derivatives as combination drugs that can be used with existing anti-malarials.

\section{Supplementary Information}

The online version contains supplementary material available at https://doi. org/10.1186/s12936-021-03632-2. 


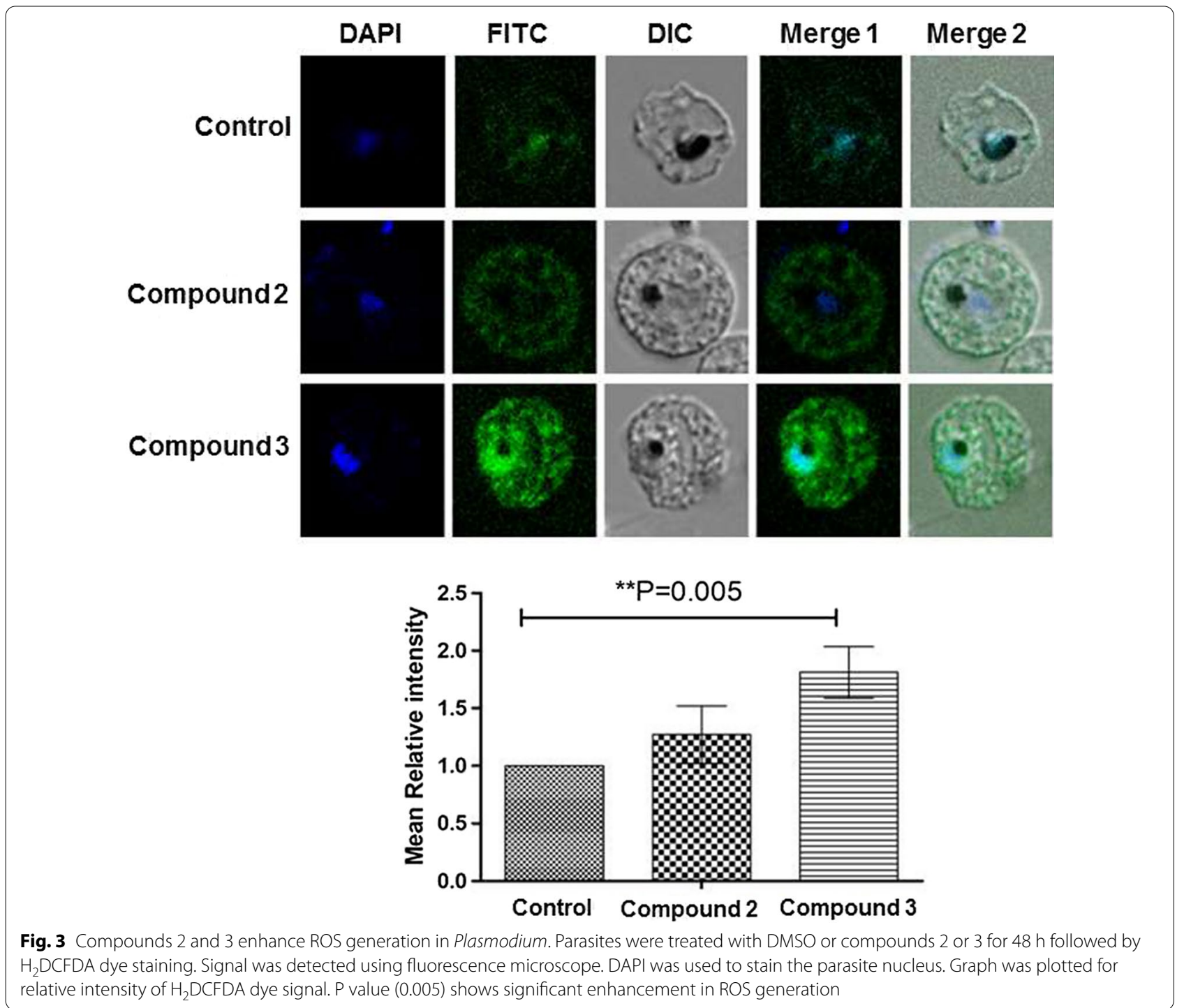

Additional file 1. Supplementary Material.

\section{Acknowledgements}

AN and HS acknowledges senior research fellowship from CSIR, India.

\section{Authors' contributions}

Study concept and design: AG; acquisition of data: AN, HS performed the experiments, CB and SS synthesized and characterized the compounds, TK and SB generated the artemisinin-resistant strain (R539T); analysis and interpretation of data: AG, SS and SB, drafting of manuscript: AG wrote the initial draft of the manuscript. SS and SB revised the manuscript. All authors read and approved the final manuscript.

\section{Funding}

We thank Shiv Nadar University for providing space and resources. University has no role in design of the study and collection, analysis, and interpretation of data and in writing the manuscript.

\section{Availability of data and materials}

All data generated or analysed during this study are included in this published article [and its additional information files].
Ethics approval and consent to participate Not applicable.

\section{Consent for publication}

Not applicable.

\section{Competing interests}

The authors declare that they have no competing interests.

\section{Author details}

1 Epigenetics \& Human Disease Laboratory, Department of Life Sciences, Shiv Nadar University, Uttar Pradesh, NH-91, Tehsil-Dadri, Greater Noida 201314, India. ${ }^{2}$ Department of Chemistry, Shiv Nadar University, Uttar Pradesh, Tehsil-Dadri, Greater Noida 201314, India. ${ }^{3}$ Special Centre for Molecular Medicine, Jawaharlal Nehru University, New Delhi, India.

Received: 10 September 2020 Accepted: 6 February 2021 Published online: 17 February 2021 


\section{References}

1. WHO. World malaria report 2019 at a glance. Geneva: World Health Organization; 2019. https://www.who.int/news-room/feature-stories/ detail/world-malaria-report-2019. Accessed 6 Jan 2021

2. Trampuz A, Jereb M, Muzlovic I, Prabhu RM. Severe malaria. Crit Care. 2003;7:315-23.

3. Shiff C. Integrated approach to malaria control. Clin Microbiol Rev. 2002;15:278-93.

4. Achan J, Talisuna AO, Erhart A, Yeka A, Tibenderana JK, Baliraine FN, et al. Quinine, an old anti-malarial drug in a modern world: role in the treatment of malaria. Malar J. 2011;10:144.

5. Tse EG, Korsik M, Todd MH. The past, present and future of anti-malarial medicines. Malar J. 2019;18:93.

6. Meshnick SR, Dobson MJ. The history of antimalarial drugs. In: Rosentha PJ, editor. Antimalarial chemotherapy: mechanisms of action, resistance and new directions in drug discovery. Totowa: Humana Press; 2001. p. 15-25.

7. WHO. Global antimalarial drug policies database-WHO African region; 2009. https://www.who.int/malaria/am_drug_policies_by_region_afro/ en/ Accessed 6 Jan 2021.

8. Model List of Essential Medicines. http://www.who.int/medicines/publi cations/essentialmedicines/en/. Accessed 6 Jan 2021.

9. Loeb F, Clark WM, Coatney GR, Coggeshall LT, Dieuaide FR, Dochez AR, et al. Activity of a new antimalarial agent, chloroquine (SN 7618). JAMA. 1946;130:1069-70.

10. Wellems TE, Plowe CV. Chloroquine-resistant malaria. J Infect Dis. 2001;184:770-6.

11. White NJ. Antimalarial drug resistance. J Clin Invest. 2004;113:1084-92.

12. Witkowski B, Lelievre J, Barragan MJ, Laurent V, Su XZ, Berry A, et al. Increased tolerance to artemisinin in Plasmodium falciparum is mediated by a quiescence mechanism. Antimicrob Agents Chemother. 2010;54:1872-7.

13. Global Partnership to Roll Back Malaria. Antimalarial drug combination therapy: report of a WHO technical consultation. Geneva: World Health Organization; 2001.

14. Antony HA, Parija SC. Antimalarial drug resistance: an overview. Trop Parasitol. 2016;6:30-41.

15. Noedl H, Socheat D, Satimai W. Artemisinin-resistant malaria in Asia. N Engl J Med. 2009;361:540-1.

16. Phyo AP, Nkhoma S, Stepniewska K, Ashley EA, Nair S, McGready R, et al. Emergence of artemisinin-resistant malaria on the western border of Thailand: a longitudinal study. Lancet. 2012;379:1960-6.

17. Woodrow CJ, White NJ. The clinical impact of artemisinin resistance in Southeast Asia and the potential for future spread. FEMS Microbiol Rev. 2017:41:34-48.

18. Schreiber SL. Target-oriented and diversity-oriented organic synthesis in drug discovery. Science. 2000;287:1964-9.

19. Spring DR. Diversity-oriented synthesis; a challenge for synthetic chemists. Org Biomol Chem. 2003;1:3867-70.

20. Galloway WR, Bender A, Welch M, Spring DR. The discovery of antibacterial agents using diversity-oriented synthesis. Chem Commun (Camb). 2009. https://doi.org/10.1039/b816852k.

21. Hideshima T, Qi J, Paranal RM, Tang W, Greenberg E, West N, et al. Discovery of selective small-molecule HDAC6 inhibitor for overcoming proteasome inhibitor resistance in multiple myeloma. Proc Natl Acad Sci USA. 2016;113:13162-7.

22. Kato N, Comer E, Sakata-Kato T, Sharma A, Sharma M, Maetani M, et al. Diversity-oriented synthesis yields novel multistage antimalarial inhibitors. Nature. 2016;538:344-9.

23. Kuo SY, Castoreno AB, Aldrich LN, Lassen KG, Goel G, Dancik V, et al. Small-molecule enhancers of autophagy modulate cellular disease phenotypes suggested by human genetics. Proc Natl Acad Sci USA. 2015;112:E4281-7.
24. Plouffe DM, Wree M, Du AY, Meister S, Li F, Patra K, et al. High-throughput assay and discovery of small molecules that interrupt malaria transmission. Cell Host Microbe. 2016:19:114-26.

25. Schreiber SL, Kotz JD, Li M, Aube J, Austin CP, Reed JC, et al. Advancing biological understanding and therapeutics discovery with small-molecule probes. Cell. 2015;161:1252-65.

26. Hati S, Sen S. Cerium chloride catalyzed, 2-iodoxybenzoic acid mediated oxidative dehydrogenation of multiple heterocycles at room temperature. Eur J Org Chem. 2017. https://doi.org/10.1002/ejoc.201601419.

27. Zheng B, Trieu TH, Meng T-Z, Lu X, Dong J, Zhang Q, Shi X-X. Cu-catalyzed mild and efficient oxidation of TH $\beta$ Cs using air: application in practical total syntheses of perlolyrine and flazin. RSC Adv. 2018;8:6834-9.

28. Mbengue A, Bhattacharjee S, Pandharkar T, Liu H, Estiu G, Stahelin RV, et al. A molecular mechanism of artemisinin resistance in Plasmodium falciparum malaria. Nature. 2015;520:683-7.

29. Kannan D, Yadav N, Ahmad S, Namdev P, Bhattacharjee S, Lochab B, et al. Pre-clinical study of iron oxide nanoparticles fortified artesunate for efficient targeting of malarial parasite. EBioMedicine. 2019;45:261-77.

30. Sen U, Saxena H, Khurana J, Nayak A, Gupta A. Plasmodium falciparum RUVBL3 protein: a novel DNA modifying enzyme and an interacting partner of essential HAT protein MYST. Sci Rep. 2018;8:10917.

31. Daina A, Michielin O, Zoete V. SwissADME: a free web tool to evaluate pharmacokinetics, drug-likeness and medicinal chemistry friendliness of small molecules. Sci Rep. 2017;7:42717.

32. Blasco B, Leroy D, Fidock DA. Antimalarial drug resistance: linking Plasmodium falciparum parasite biology to the clinic. Nat Med. 2017;23:917-28.

33. Su XZ, Lane KD, Xia L, Sa JM, Wellems TE. Plasmodium genomics and genetics: new insights into malaria pathogenesis, drug resistance, epidemiology, and evolution. Clin Microbiol Rev. 2019;32:e00019-19.

34. Collins I, Jones AM. Diversity-oriented synthetic strategies applied to cancer chemical biology and drug discovery. Molecules. 2014;19:17221-55.

35. Galloway WR, Isidro-Llobet A, Spring DR. Diversity-oriented synthesis as a tool for the discovery of novel biologically active small molecules. Nat Commun. 2010;1:80.

36. Gerry CJ, Schreiber SL. Chemical probes and drug leads from advances in synthetic planning and methodology. Nat Rev Drug Discov. 2018;17:333-52.

37. Singh TP, Singh OM. Recent progress in biological activities of indole and indole alkaloids. Mini Rev Med Chem. 2018;18:9-25.

38. Thanikachalam PV, Maurya RK, Garg V, Monga V. An insight into the medicinal perspective of synthetic analogs of indole: a review. Eur J Med Chem. 2019:180:562-612

39. Kgokong JL, Smith PP, Matsabisa GM. 1,2,4-Triazino-[5,6b]indole derivatives: effects of the trifluoromethyl group on in vitro antimalarial activity. Bioorg Med Chem. 2005;13:2935-42.

40. Schuck DC, Jordao AK, Nakabashi M, Cunha AC, Ferreira VF, Garcia CR. Synthetic indole and melatonin derivatives exhibit antimalarial activity on the cell cycle of the human malaria parasite Plasmodium falciparum. Eur J Med Chem. 2014;78:375-82.

41. Luthra T, Nayak AK, Bose S, Chakrabarti S, Gupta A, Sen S. Indole based antimalarial compounds targeting the melatonin pathway: their design, synthesis and biological evaluation. Eur J Med Chem. 2019;168:11-27.

42. Santos SA, Lukens AK, Coelho L, Nogueira F, Wirth DF, Mazitschek R, et al. Exploring the 3-piperidin-4-yl-1H-indole scaffold as a novel antimalarial chemotype. Eur J Med Chem. 2015;102:320-33.

43. Pinheiro LCS, Feitosa LM, Silveira FFD, Boechat N. Current antimalarial therapies and advances in the development of semi-synthetic artemisinin derivatives. An Acad Bras Cienc. 2018;90:1251-71.

\section{Publisher's Note}

Springer Nature remains neutral with regard to jurisdictional claims in published maps and institutional affiliations. 